\title{
General anaesthesia related mortality in a limited resource settings region: a retrospective study in two teaching hospitals of Butembo
}

\author{
Furaha Nzanzu Blaise Pascal ${ }^{1,2^{*}}$, Agnes Malisawa ${ }^{3}$, Andreas Barratt-Due $^{4}$, Felix Namboya ${ }^{1}$ and Gregor Pollach ${ }^{1}$
}

\begin{abstract}
Background: General anaesthesia (GA) in developing countries is still a high-risk practice, especially in Africa, accompanied with high morbidity and mortality. No study has yet been conducted in Butembo in the Democratic Republic of the Congo to determine the mortality related to GA practice. The main objective of this study was to assess mortality related to GA in Butembo.

Methods: This was a retrospective descriptive and analytic study of patients who underwent surgery under GA in the 2 main teaching hospitals of Butembo from January 2011 to December 2015. Data were collected from patients files, anaesthesia registries and were analysed with SPSS 26.

Results: From a total of 921 patients, 539 (58.5\%) were male and 382 (41.5\%) female patients. A total of 83 (9.0\%) patients died representing an overall perioperative mortality rate of 90 per 1000. Out of the 83 deaths, 38 occurred within $24 \mathrm{~h}$ representing GA related mortality of 41 per 1000. There was a global drop in mortality from 2011 to 2015. The risk factors of death were: being a neonate or a senior adult, emergency operation, ASA physical status $>2$ and a single deranged vital sign preoperatively, presenting any complication during GA, anaesthesia duration > 120 minutes as well as visceral surgeries/laparotomies. Ketamine was the most employed anaesthetic.

Conclusion: GA related mortality is very high in Butembo. Improved GA services and outcomes can be obtained by training more anaesthesia providers, proper patients monitoring, improved infrastructure, better equipment and drugs procurement and considering regional anaesthesia whenever possible.
\end{abstract}

\section{Background}

General anaesthesia (GA) in developing countries is still a high-risk practice [1-3]. The practice faces numerous challenges exclusively related to high number of pathologies, shortage of material and drugs, infrastructure

\footnotetext{
* Correspondence: blaisepascal.furaha@gmail.com

'Department of Anaesthesia and Intensive Care, College of Medicine, University of Malawi, Blantyre, Malawi

${ }^{2}$ Faculty of Medicine, Université Catholique du Graben, Butembo, Democratic Republic of the Congo

Full list of author information is available at the end of the article
}

and human resources $[2,4,5]$. In addition, a very dysfunctional health system is worsening the situation in Sub-Saharan Africa. However, the presence of adequate infrastructure, skilled anaesthesia providers and the use of effective sanitation are paramount to improve the anaesthesia outcome [6-8].

Several investigators have reported that anaesthesiarelated morbidity and mortality rates have declined overtime, which have been attributed to a variety of safety improvements. This include advances in training, improved monitoring techniques, development and

(c) The Author(s). 2021, corrected publication [2021]. Open Access This article is licensed under a Creative Commons

Attribution 4.0 International License, which permits use, sharing, adaptation, distribution and reproduction in any medium or format, as long as you give appropriate credit to the original author(s) and the source, provide a link to the Creative Commons licence, and indicate if changes were made. The images or other third party material in this article are included in the article's Creative Commons licence, unless indicated otherwise in a credit line to the material. If material is not included in the article's Creative Commons licence and your intended use is not permitted by statutory regulation or exceeds the permitted use, you will need to obtain permission directly from the copyright holder. To view a copy of this licence, visit http://creativecommons.org/licenses/by/4.0/. The Creative Commons Public Domain Dedication waiver (http:// creativecommons.org/publicdomain/zero/1.0/) applies to the data made available in this article, unless otherwise stated in a credit line to the data. 
widespread adoption of practice evidence-based guidelines, and other systematic approaches to error reduction such as checklists and procedures protocols, airway management tools, sharing of safety knowledge and peer review, labelling of drugs, teamwork and simulation [7, 9-13].

A comparison of the reports from different countries in the period 1954-1989 with 1990-2006 reflects a decrease in anaesthesia-related mortality rates from $0.03-$ 0.79 per 1000 anaesthetics to $0.01-0.57$ per 1000 anaesthetics in developed countries. Studies from 2010 to date have reported similar rates with variations from country to country [2, 14-18].

However, in developing countries of Africa, mortality rates are still higher than in developed countries $[6,7$, 11, 19-22]. The downward trend observed worldwide seems not to be as effective in Africa. For instance, in Zambia, avoidable mortality rate was still unchanged (32\%) from 1989 to 2012 [23, 24]. In Malawi in 2000, Hansen et al. reported 51 complications and 14 deaths in 3022 anaesthetics during a period of 6 months. Eleven of the 14 deaths were identified as avoidable with an avoidable mortality rate (AMR) of 1:275. Considering factors of these deaths, anaesthesia-related mortality represented an AMR of 1:504 which was higher than in developed countries [20]. The intraoperative mortality rate in Malawi is still high and had not improved over time when comparing data from 2004 to 2006 with 20152016 [25]. In Ivory Coast during the same period, the mortality was 3.9 per 1000 patients who were anesthetized and was still very high [21]. In Togo, the $24 \mathrm{~h}$ mortality rate including all causes was 25.7 per 1000 anaesthetics, with anaesthesia AMR of 1:133 in 2002. It decreased to 8.9 per 1000 in 2006 . The drop was associated with increased number of physician providers, initiation of anaesthesia preoperative clinics, creation of postoperative anaesthesia care unit (PACU) and practice of loco-regional anaesthesia [26, 27].

In the Democratic Republic of the Congo (DRC), Davies et al. reported a $48 \mathrm{~h}$ anaesthesia mortality rate of 8.67 per 1000 which was less than the rates observed in South Soudan (17.81) and in the Central African Republic (15.20) [28]. Studies conducted in obstetrics have reported high rates of maternal and neonatal mortality directly or indirectly associated with anaesthesia $[29,30]$.

GA remains widely used in hospitals in the DRC. According to Ahuka OL, up to $35.2 \%$ of surgeries are done under GA in the DRC and it is likely to be the same in Butembo, a City in the North Kivu Province in the eastern part of the DRC [31]. Morbidity and mortality related to GA directly or indirectly remain high in the DRC [28, 30, 31]. Although the documentation from general surgery are scarce, a few obstetrics studies largely prove this situation. Maternal mortality rate of up to 20 for 1000 associated directly or partially have been reported [29]. Furaha et al. conducted a 3 years study (2011 to 2013) about maternal mortality in four hospitals directed by the "Bureau Diocésain des oeuvres médicales" (BDOM) within 2 hospitals in Butembo and 2 others around Butembo. They found that 9 out of 14 maternal deaths that occurred in 56 women with complications after caesarean section were associated with GA [30].

Furthermore, GA is a veritable problem in Butembo for several reasons. Lack of human resources is the major one. In the whole city of Butembo there is no physician specialized in anaesthesiology, and in practice, anaesthesia is managed either by ordinary nurses or surgeons. Nevertheless, few hospitals in the city have anaesthetic nurses. The other reasons are infrastructure constraints as well as lack of drugs, monitoring equipment and specific rooms for postoperative care. These problems, together, lead to unsafe and poor quality of anaesthesia services in Butembo. The aim of this study was to describe the practice of GA and determine the outcomes and risk factors of death of patients undergoing surgery under GA in Butembo.

\section{Methods}

This research was conducted in the two main teaching hospitals associated with the "Université Catholique du Graben" (UCG) of Butembo City: the Matanda hospital of Butembo and, the "Cliniques Unversitaires du Graben" (CUG), both in North Kivu Province in DRC.

Butembo is a City of the North Kivu Region lying West of Ruwenzori Mount and Virunga National Park in the eastern part of the DRC. Butembo is at an altitude of $1736 \mathrm{~m}$ and close to the Equator line at latitude of $0^{\circ} 08^{\prime} 29^{\prime \prime}$ North and longitude of $29^{\circ} 17^{\prime} 28^{\prime \prime}$ East. Butembo has approximately 900,000 inhabitants.

This was a retrospective descriptive and analytic study of 5 years from January 2011 to December 2015. The population included all patients who underwent an operation under GA during the study period in the 2 hospitals.

The sample size was an exhaustive probability sampling using Slovin's formula with confidence interval of 99\%. All patients whose files were available, surgery or gynaecologic procedure performed under GA with American Society of Anesthesiologists Physical Status (ASA PS) equal or lower than 4 were included. Obstetric cases and patients of ASA PS 5 and above were exluded. Enquiries from the hospitals revealed that 1015 files of patients who received GA during the period of interest were available, of which 198 (19.5\%) were from UCG and 817 (80.5\%) from Matanda Hospital. A sample size of 921 was calculated and used. The sample was 
proportional to the cases found in each hospital and patients were systematically included in each sample proportion.

Data were collected using a data collection form designed for the study. Information was obtained from the anaesthetic registers, the anaesthetic personal file, and patient's files. When a patient was operated on several times during the same hospital stay, only the last operation was included in the study whereas the other operations were considered as part of the history. Preoperative, intraoperative and postoperative variables were recorded.

Preoperative variables included patient-related variables such as age, gender, ASA PS, and surgery and anaesthetic histories, urgency of the procedure, preoperative assessment, vital signs, and the date of admission. Intraoperative anaesthetic variables included the anaesthetic provider qualification and experience; type of anaesthetic agents used for induction; definitive airway management, type of agent used for maintenance, and surgical variables such as type of surgery, time and duration of the procedure. Postoperative variables included postoperative recovery location, complications after surgery, postoperative outcome, time and place of death, and date of discharge. Any anaesthetized patient who died during the surgery or within $24 \mathrm{~h}$ after the procedure, was defined as an "anaesthesia-related" death. No other causality was further sough to judge if the death was partially or fully associated to death. All patients who died after $24 \mathrm{~h}$ represented the "After $24 \mathrm{~h}$ mortality". The overall perioperative mortality was defined as all patients who died after a surgery under GA regardless the time.

Data were entered and analysed with SPSS Version 26. Descriptive statistics were used to describe variables. Logistic regression was used to determine the degree of association between the dependent variable (mortality) and independent variables (others variables). Associations were established using the Chi-square test of Pearson with a $p$-value below 0.05 considered as statistically significant. Odds ratio (OR) and/or Relative risk (RR) were calculated when necessary with their confidence intervals at $95 \%$ (95\% CI).

This study was a low-risk research. The protocol was submitted and obtained approval from the "the Comité Ethique du Nord Kivu" (CENK) in Butembo in the DRC under number CENK N ${ }^{\circ} 007 / 2018$ and from the College of Medicine Research Ethics Committee (COMREC) in Malawi under number P.07/18/2431. Participants' consent was waived by both Ethics committees. The data were anonymous on the data collecting form and in the electronic Data Base. All research was performed in accordance with relevant guidelines/regulations in these hospitals.

\section{Results}

In total, 921 patients were included the present study, $741(80.5 \%)$ from the Matanda hospital represented and 180(19.5\%) from the CUG, altogether 539 (58.5\%) males and $382(41.5 \%)$ females. The sex ratio was 1.4 for males. A total of $83(9.0 \%)$ patients died which represented an overall perioperative mortality rate after a surgery under GA of 90 per 1000. From the 83 deaths, 38 deaths $(45.8 \%)$ occurred within $24 \mathrm{~h}$ representing a GA related mortality (directly or indirectly) of $4.1 \%(38 / 921)$ or 41 per 1000 . Four patients $(4.8 \%)$ died at induction and 5 (6.0\%) died during maintenance. Fifty-two patients (62.7\%) died in the ICU against 1 in PACU (Table 1). There was a significant difference in places of death with more patients dying at the ICU (Hypothesis Test, $p<$ 0.0001 ). There was a significant global drop trend in mortality from 2011 to 2015 (calculated $\mathrm{X}^{2}=9.80(\mathrm{df}=$ $4), p=0.04$ ) (Fig. 1). The trendline was significantly negative at the Matanda Hospital $\left(\mathrm{X}^{2}=16.75 ; \mathrm{df}=4 ; p=\right.$ 0.002 ) (Fig. 2). The positive trendline observed at the CUG over years was not significant $(\mathrm{X} 2=1.64 ; \mathrm{df}=4$; $p=0.80$ ) (Fig. 3).

Male patients died more frequently compared to female patients $(p=0.04)$. The median of age was 20 years with a minimum of 1 day and maximum of 90 years. There was a significant association between age and mortality $\left(x^{2}\right.$ 43.14; $p<0.0001)$. The extreme ages were associated with increased risk of mortality. Neonates had 8.09 risk of dying compared to young adults (16-30 years old) $(p<$ $0.0001)$. The risk of dying was increased by 3.08 for senior adults ( $\geq 51$ years old) compared to young adults $(p=$ 0.002) (Table 2).

The preoperative assessment was not done for 81 patients $(8.8 \%)$ but this didn't represent a factor of risk

Table 1 Perioperative mortality under general anaesthesia

\begin{tabular}{lll}
\hline Issue & Patients $(\boldsymbol{N}=\mathbf{9 2 1})$ & $\mathbf{\%}$ \\
\hline Recovery & 838 & 91.0 \\
Death (Overall mortality) & 83 & 9.0 \\
Mortality according to time & $\mathbf{N = 8 3}$ & \\
24H mortality (GA related mortality) & 38 & 45.8 \\
After 24H mortality & 45 & 54.2 \\
Moment of Death & $\mathbf{N}=\mathbf{8 3}$ & \\
At induction & 4 & 4.8 \\
During maintenance & 5 & 6.0 \\
$\quad$ Postoperatively & 74 & 89.2 \\
Place of death in the hospital & $\mathbf{N}=\mathbf{8 3}$ & \\
$\quad$ Intensive care & 52 & 62.7 \\
Patient Room/Ward & 16 & 19.3 \\
Operating Room & 14 & 16.9 \\
Postoperative care unit & 1 & 1.2 \\
\hline
\end{tabular}




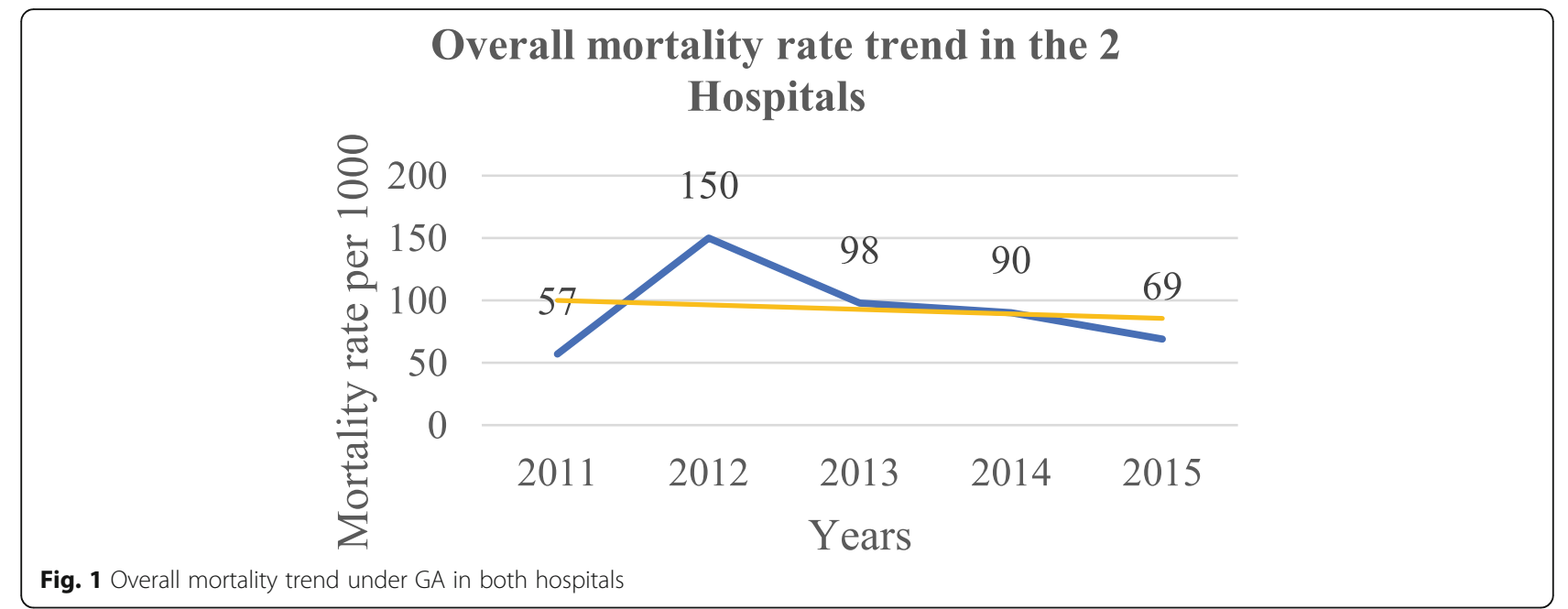

of mortality ( $p=0.48)$. The emergency of the operation increased the risk by 4.48 ( $\mathrm{p}<0.0001)$ compared to nonemergency procedures. Previous surgery or GA were not associated with greater risk of death $(p=0.37$ and $p=$ 0.12 respectively). The risk of death increased significantly as ASA PS increased from 2 to 4 . Patients with ASA PS 3 and ASA PS 4 had the highest risk of death. The presence of only one single deranged vital sign preoperatively represented 3.09 risk of death compared to patients with normal vital signs before operation $(p<$ 0.0001) (Table 3). Premedication was given to $835(90.7 \%)$ patients and was primarily $(85.1 \%)$ atropine based (atropine alone 75.5\%, atropine+diazepam 9.1\%, Atropine+other drugs $0.5 \%$ ). Diazepam and midazolam alone were given as premedication to $3.6 \%$ and $1,8 \%$ patients respectively. Two patients received promethazine or dexamethasone as premedication drug whereas 9.3\% of the patients did not receive any premedication.
Trained anaesthetic nurses conducted 873(94.8\%) anaesthesia procedures. They were involved in $81(97.5 \%)$ deaths of the 83 deaths. The qualification of the anaesthesia provider was not associated with risk of dying in this study $(p=0.59)$. Anaesthesia providers with experience of more than 5 years conducted $468(50.8 \%)$ anaesthesia procedures and were involved in $41(49.3 \%)$ of the 83 deaths. Experience was not associated with increased risk of death $(p=0.37)$ (Table 4$)$.

Gas induction with halothane was given to $142(15.4 \%)$ patients of whom 21 died. Compared to patients who had a parenteral induction, gas induction increased the risk of death by $2.01(p=0.009)$. Ketamine was the agent of induction for 526 patients of 779(67.5\%) parenteral inductions. Intubation was performed for $440(47.8 \%)$ patients and 52(62.7\%) of 83 deaths occurred in intubated patients. Intubation increased the risk of death by 1.94 compared to non-intubated patients $(p=0.004)$ (Table 5).

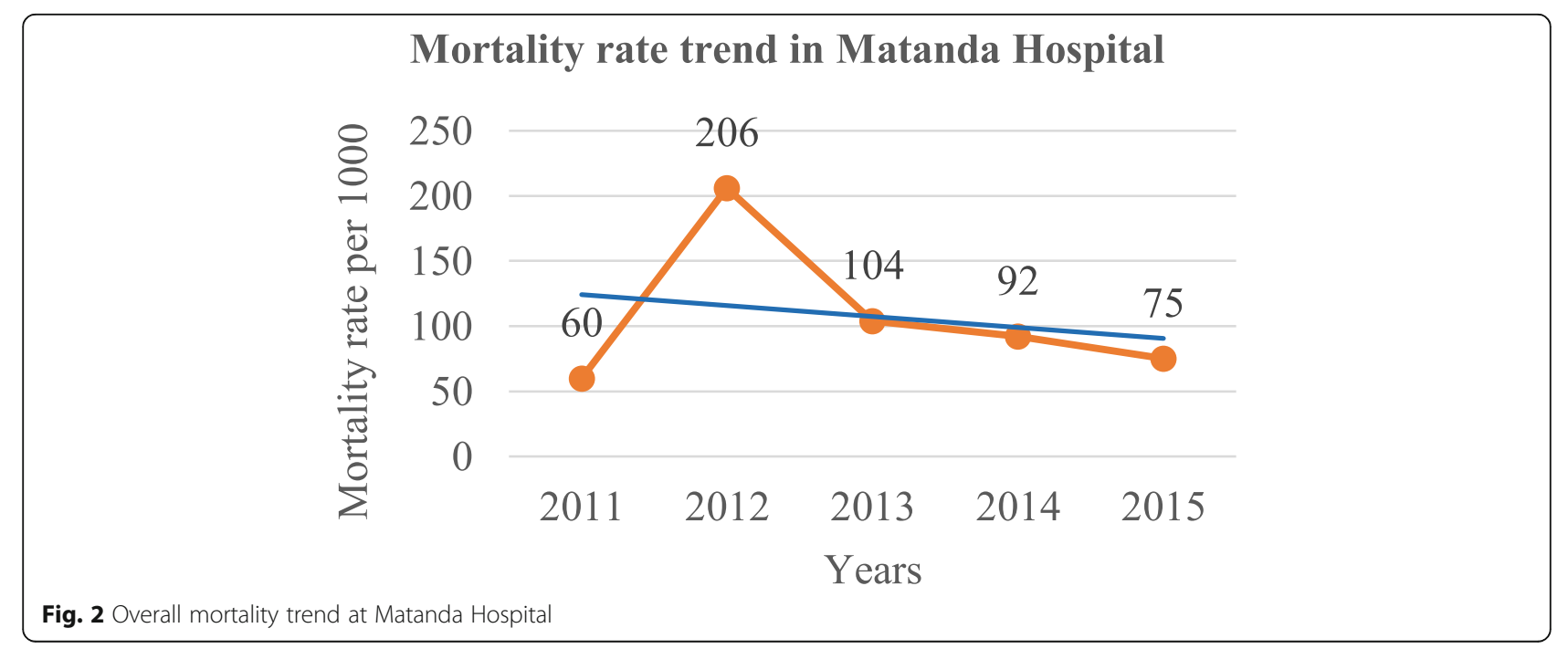




\section{Mortality rate trend at the CUG}

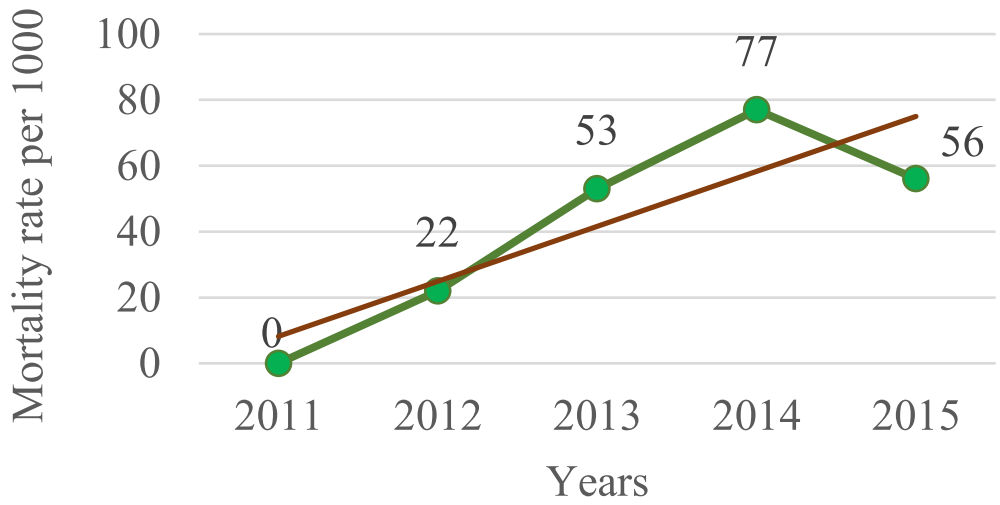

Fig. 3 Overall mortality trend at CUG

Ketamine was the first drug used for maintenance of anaesthesia in 381 patients (41.4\%) followed by halothane used for 227 patients (24.6\%). Isoflurane, thiopental and propofol were used in 195(21.2\%), 110(11.9\%) and $8(0.9 \%)$ cases respectively. Gas maintenance of anaesthesia, performed in $422(45.8 \%)$ out of 921 patients, accounted for $47(11.1 \%)$ deaths in this group. Gas maintenance was associated with increased risk of mortality $(\mathrm{OR}=1.61, p=0.04)$ compared to iv maintenance. Complications during maintenance of anaesthesia were recorded in $14.4 \%$ of the patients (133/921), involving 33 patients (24.8\%) and represented a highly increased risk of death $(\mathrm{OR}=21.3, p<0.0001)$. Hypotension and vomiting were the most frequent complications, both observed in 9 patients (6.8\%), whereas only hypotension during maintenance was associated with increased mortality (OR $=24.5, p<0.0001)$. Cardiac arrest and cardiorespiratory arrest were both fatal complications during maintenance of anaesthesia (Table 6).
The mean duration of anaesthesia was $81.1 \mathrm{~min}$ with a standard deviation of $50.8 \mathrm{~min}$ (min. 10, max. $360 \mathrm{~min}$ ). Duration of anaesthesia was associated with increased risk of death $\left(\mathrm{x}^{2}=39.1 ; \mathrm{df}=3 ; p<0.0001\right)$ with a higher risk of death the longer the procedure lasted. The type of surgery performed was significantly associated with risk of death $\left(\left(\mathrm{X}^{2}=96.5 ; \mathrm{df}=10 ; p<0.0001\right)\right.$. Visceral surgeries/laparotomies increased the risk of patient death compared to orthopaedic surgeries $(\mathrm{OR}=7.3, \mathrm{p}=$ $<0.0001$ ) (Table 7).

Postoperative vital signs were deranged for 324(35.5\%) patients. Deranged postoperative vital signs increased the risk of death by $4.98(p=0.0001)$. A total of $500(64.5 \%)$ patients were admitted directly in their wards after operation. Nine patients (1\%) were left in theatre postoperatively. There was an association between the recovery location and death $\left(x^{2}=102.68 ; \mathrm{df}=3 ; p=\right.$ 0.0001 ). Patients having their recovery in theatre had 76 times as much chance of dying compared to patients

Table 2 Mortality according to gender and age of patients

\begin{tabular}{|c|c|c|c|c|c|c|}
\hline Variables & Patients & $\%$ & $\begin{array}{l}\text { Deaths } \\
\text { (\%) }\end{array}$ & $\mathrm{X}^{2}$ & $p$-value & OR (95\% Cl) \\
\hline \multicolumn{7}{|l|}{ Gender } \\
\hline Male & 539 & 58.5 & $57(10.6)$ & 3.87 & 0.04 & $1.62(0.99-2.62)$ \\
\hline Female & 382 & 41.5 & $26(6.8)$ & & & 1 \\
\hline Total & 921 & 100.0 & $83(9.0)$ & 3.87 & 0.04 & \\
\hline \multicolumn{7}{|l|}{ Age group } \\
\hline 0-30 days & 29 & 3.1 & $10(34.5)$ & 22.08 & 0.0001 & $8.03(3.02-21.39)$ \\
\hline 31 days-2 years & 163 & 17.7 & $15(9.2)$ & 1.54 & 0.29 & $1.54(0.68-3.47)$ \\
\hline $3-15$ years & 209 & 22.7 & $7(3.3)$ & 1.70 & 0.19 & $0.52(0.20-1.39)$ \\
\hline $16-30$ years & 179 & 19.5 & $11(6.1)$ & & & 1 \\
\hline $31-50$ years & 204 & 22.1 & $17(8.3)$ & 0.67 & 0.41 & $1.38(0.63-3.04)$ \\
\hline$\geq 51$ years & 137 & 14.9 & 23(16.8) & 9.16 & 0.002 & $3.08(1.44-6.56)$ \\
\hline Total & 921 & 100.0 & $83(9.0)$ & 43.14 & 0.0001 & \\
\hline
\end{tabular}


Table 3 Mortality according to preoperative parameters and mortality

\begin{tabular}{|c|c|c|c|c|c|c|}
\hline Parameters & $\begin{array}{l}\text { Patients } \\
N=921\end{array}$ & $\%$ & $\begin{array}{l}\text { Deaths } \\
\text { (\%) }\end{array}$ & $\mathrm{x}^{2}$ & $p$-value & OR $(95 \% \mathrm{Cl})$ \\
\hline \multicolumn{7}{|c|}{ Pre-anaesthetic Assessment } \\
\hline Yes & 840 & 91.2 & $74(8.8)$ & & & 1 \\
\hline No & 81 & 8.8 & $9(11.1)$ & 0.5 & 0.48 & $1.29(0.62-2.69)$ \\
\hline \multicolumn{7}{|l|}{ History of surgery } \\
\hline Yes & 324 & 35.2 & $33(10.1)$ & 0.79 & 0.37 & 1.23(0.77-1.96) \\
\hline No & 597 & 64.8 & $50(8.4)$ & & & 1 \\
\hline \multicolumn{7}{|l|}{ History of GA } \\
\hline Yes & 265 & 28.8 & $30(11.2)$ & 2.3 & 0.12 & $1.44(0.90-2.31)$ \\
\hline No & 656 & 71.2 & $53(8.1)$ & & & 1 \\
\hline \multicolumn{7}{|c|}{ Urgency of procedure } \\
\hline Emergency & 198 & 21.5 & $42(21.2)$ & 45.8 & 0.0001 & $4.48(2.81-7.12)$ \\
\hline Non-Emergency & 723 & 78.5 & $41(5.7)$ & & & 1 \\
\hline \multicolumn{7}{|c|}{ ASA Physical Status } \\
\hline ASA 1 & 378 & 41.0 & $5(1.3)$ & & & 1 \\
\hline ASA 2 & 409 & 44.4 & $30(34.2)$ & 16.7 & 0.0001 & $5.90(2.26-15.38)$ \\
\hline ASA 3 & 111 & 12.1 & $38(34.2)$ & 115.8 & 0.0001 & $38.83(14.78-101.98)$ \\
\hline ASA 4 & 23 & 2.5 & $10(43.5)$ & 107.0 & 0.0001 & $57.38(17.15-191.97)$ \\
\hline \multicolumn{7}{|l|}{ Vital signs } \\
\hline Normal & 697 & 75.7 & $40(5.7)$ & & & 1 \\
\hline Deranged & 224 & 24.3 & $43(19.2)$ & 37.4 & 0.0001 & $3.90(2.46-6.18)$ \\
\hline
\end{tabular}

who were admitted in PACU postoperatively. Postoperative complications for the 912 patients who reached the postoperative period were presented among 159 patients representing a postoperative morbidity rate of $17.4 \%$ and were highly associated with increased mortality $\left(X^{2}=310.17 ; \quad d f=1 ; \quad\right.$ OR $\left.=93.03 ; \quad p<0.0001\right)$ (Table 8). Paracetamol alone was the most employed drug for postoperative pain control followed by the combination of paracetamol and diclofenac injection. Metamizole was used for $6.2 \%$ of patients (Fig. 4).

\section{Discussion}

This study described GA related mortality among patients undergoing surgery in Butembo. For our knowledge, this is the first study to evaluate the practice of GA in its all aspects in the region. As a baseline study, it elucidates the situation and the practice of GA in the region, the profile of patients, the anaesthesia providers' qualifications and experience and the common drugs used. Additionally, this study documents the frequent complications and the outcome of patients operated

Table 4 Mortality according to qualification and experience of the anaesthesia provider

\begin{tabular}{|c|c|c|c|c|c|c|}
\hline Parameters & $\begin{array}{l}\text { Patients } \\
N=921\end{array}$ & $\%$ & $\begin{array}{l}\text { Deaths } \\
\text { (\%) }\end{array}$ & $\mathrm{X}^{2}$ & $p$-value & OR $(95 \% \mathrm{Cl})$ \\
\hline \multicolumn{7}{|l|}{ Anaesthesia Provider } \\
\hline Anaesthetic Nurse & 873 & 94.8 & $81(9.3)$ & & & 1 \\
\hline Any nurse & 33 & 3.6 & $1(3.0)$ & 1.50 & 0.21 & $0.30(0.04-2.26)$ \\
\hline Trainee Anaesthetic nurse & 11 & 1.2 & $1(9.1)$ & 0.00 & 0.98 & $0.97(0.12-7.73)$ \\
\hline Any Doctor & 4 & 0.4 & 0 & & & \\
\hline \multicolumn{7}{|l|}{ Provider work experience } \\
\hline Less than 1 year & 45 & 4.9 & $5(11.1)$ & 0.27 & 0.59 & $1.31(0.48-3.48)$ \\
\hline $1-2$ years & 189 & 20.5 & $22(11.6)$ & 1.28 & 0.25 & $1.37(0.79-2.37)$ \\
\hline $3-4$ years & 219 & 23.8 & $15(6.8)$ & 0.72 & 0.39 & $0.77(0.41-1.41)$ \\
\hline Equal or more than 5 years & 468 & 50.8 & $41(8.8)$ & & & 1 \\
\hline
\end{tabular}


Table 5 Factors of mortality at induction

\begin{tabular}{|c|c|c|c|c|c|c|}
\hline Parameters & Patients $(N=921)$ & $\%$ & Deaths (\%) & $x^{2}$ & $p$-value & OR $(95 \% \mathrm{Cl})$ \\
\hline \multicolumn{7}{|l|}{ Route of GA induction } \\
\hline Parenteral (IV/IM) & 779 & 84.6 & $62(7.9)$ & & & 1 \\
\hline Inhalation & 142 & 15.4 & $21(14.8)$ & 6.83 & 0.009 & $2.01(1.18-3.41)$ \\
\hline IV/IM Anaesthetics & $N=779$ & & & & & \\
\hline Ketamine & 526 & 67.5 & $44(8.4)$ & & & \\
\hline Thiopental & 240 & 30.8 & $11(6.7)$ & & & \\
\hline Propofol & 13 & 1.7 & $2(15.4)$ & & & \\
\hline Airway Management & $N=921$ & & & & & \\
\hline No intubation & 481 & 52.2 & $31(6.4)$ & & & 1 \\
\hline Oro-tracheal Intubation & 440 & 47.8 & $52(11.8)$ & 8.09 & 0.004 & $1.94(1.22-3.09)$ \\
\hline Complications at induction & $N=789$ & & & & & \\
\hline Yes & 24 & 3.0 & $8(33.3)$ & 14.22 & 0.002 & $4.74(1.96-14.45)$ \\
\hline No & 765 & 97.0 & $73(9.5)$ & & & 1 \\
\hline \multicolumn{7}{|l|}{ Type of complications } \\
\hline None & 765 & 97.0 & $73(9.5)$ & & & 1 \\
\hline Hypotension & 12 & 1.5 & $2(16.7)$ & 0.68 & 0.41 & $1.89(0.41-8.81)$ \\
\hline cardio-respiratory arrest & 4 & 0.5 & $4(100)$ & 36.13 & 0.0001 & $10.47(8.42-13.03)^{a}$ \\
\hline Vomiting & 3 & 0.4 & $1(33.3)$ & 1.94 & 0.16 & $4.73(0.42-17.56)$ \\
\hline Difficult intubation & 3 & 0.4 & $0(0)$ & & & \\
\hline Cardiac arrest & 1 & 0.1 & $1(100)$ & 9.36 & 0.002 & $10.47(8.42-13.03)^{a}$ \\
\hline Hypertension & 1 & 0.1 & $0(0)$ & & & \\
\hline
\end{tabular}

${ }^{\mathrm{a}}$ Relative risk

Table 6 GA maintenance strategies, complications and mortality

\begin{tabular}{|c|c|c|c|c|c|c|}
\hline Parameter & Patients & $\%$ & Deaths (\%) & $x^{2}$ & $p$-value & OR $(95 \% \mathrm{Cl})$ \\
\hline \multicolumn{7}{|l|}{ Type of maintenance } \\
\hline Gas Maintenance & 422 & 45.8 & $47(11.1)$ & 4.29 & 0.04 & $1.61(1.02-2.54)$ \\
\hline IV Maintenance & 499 & 54.2 & $36(7.2)$ & & & 1 \\
\hline \multicolumn{7}{|l|}{ Maintenance complication } \\
\hline Yes & 33 & 24.8 & $2(2.0)$ & 24.2 & 0.0001 & $21.3(4.36-103.91)$ \\
\hline No & 100 & 75.2 & 10(30.3) & & & \\
\hline \multicolumn{7}{|l|}{ Type of complication } \\
\hline None & 100 & 75.2 & $2(2.0)$ & & & 1 \\
\hline Hypotension & 9 & 6.8 & $3(33.3)$ & 18.5 & 0.0001 & $24.50(3.41-175.67)$ \\
\hline Vomiting & 9 & 6.8 & $1(11.1)$ & 2.6 & 0.10 & $6.12(0.49-75.09)$ \\
\hline Hypertension & 6 & 4.5 & $1(16.5)$ & 4.4 & 0.03 & $9.80(0.75-127.17)$ \\
\hline Respiratory arrest & 3 & 2.2 & $0(0)$ & & & \\
\hline Cardio-respiratory arrest & 3 & 2.2 & $3(100.0)$ & 60.6 & 0.0001 & $50.00(12.68-197.16)^{*}$ \\
\hline Cardiac arrest & 2 & 1.5 & $2(100.0)$ & 49.9 & 0.0001 & $50.00(12.68-197.16)^{*}$ \\
\hline Accidental extubation & 1 & 0.8 & $0(0)$ & & & \\
\hline
\end{tabular}


Table 7 Mortality according to duration of anaesthesia and type of surgery

\begin{tabular}{|c|c|c|c|c|c|c|}
\hline Parameters & Patients $N=921$ & $\%$ & Deaths (\%) & $\mathrm{X}^{2}$ & $p$-value & OR $(95 \% \mathrm{Cl})$ \\
\hline \multicolumn{7}{|l|}{ Duration of Anaesthesia (Minutes) } \\
\hline$\leq 60$ & 441 & 47.9 & $24(5.4)$ & & & 1 \\
\hline $61-120$ & 341 & 37.0 & 28(8.2) & 2.37 & 0.12 & $1.6(0.9-2.7)$ \\
\hline $121-150$ & 91 & 9.9 & 18(19.8) & 21.32 & 0.000 & $4.3(2.2-8.3)$ \\
\hline$>150$ & 48 & 5.2 & $13(27.1)$ & 28.98 & 0.000 & $6.6(3.0-13.8)$ \\
\hline \multicolumn{7}{|l|}{ Type of Surgery } \\
\hline Visceral surgery/laparotomy & 304 & 33,0 & $64(21.0)$ & 22.71 & 0.000 & 7.3(2.9-18.6) \\
\hline Orthopaedic & 142 & 15,4 & $5(3.5)$ & & & 1 \\
\hline ENT & 126 & 13,7 & $1(0.8)$ & 2.66 & 0.13 & $0.2(0.0-1.9)$ \\
\hline Hernia & 124 & 13,5 & $1(0.8)$ & 2.21 & 0.13 & $0.2(0.0-1.9)$ \\
\hline Others & 78 & 8,5 & $4(5.1)$ & 0.33 & 0.56 & $1.5(0.3-5.6)$ \\
\hline Plastics & 43 & 4,7 & $1(2.3)$ & 0.15 & 0.69 & $0.6(0.1-5.4)$ \\
\hline Gynaecology & 34 & 3,7 & $0(0)$ & & & \\
\hline Urology & 26 & 2,8 & $0(0)$ & & & \\
\hline Ano-rectal malformations & 26 & 2,8 & $6(23.1)$ & 13.73 & 0.000 & $8.2(2.3-29.5)$ \\
\hline EUA & 9 & 1,0 & $0(0)$ & & & \\
\hline Neurology & 9 & 1,0 & $1(11.1)$ & 1.27 & 0.25 & $3.4(0.4-32.9)$ \\
\hline
\end{tabular}

Table 8 Postoperative complications and death

\begin{tabular}{|c|c|c|c|c|c|c|}
\hline Postoperative parameters & $\begin{array}{l}\text { Patients } \\
N=912\end{array}$ & $\%$ & Deaths (\%) & $x^{2}$ & $p$-value & OR $(95 \% \mathrm{Cl})$ \\
\hline \multicolumn{7}{|l|}{ Vital signs } \\
\hline Normal & 597 & 64.8 & $25(4.2)$ & & & 1 \\
\hline Deranged & 324 & 35.2 & $58(17.9)$ & 48.16 & 0.000 & $4.98(3.05-8.15)$ \\
\hline \multicolumn{7}{|l|}{ Recovery location } \\
\hline Ward & 500 & 54.3 & $17(3.4)$ & 2.15 & 0.14 & $0.33(0.07-1.55)$ \\
\hline Intensive care & 391 & 42.4 & $56(14.3)$ & 0.37 & 0.53 & $1.58(0.36-7.00)$ \\
\hline PACU & 21 & 2.3 & $2(9.5)$ & & & 1 \\
\hline Operating room & 9 & 1.0 & $8(88.9)$ & 17.85 & 0.0001 & $76.00(6.00-962.32)$ \\
\hline \multicolumn{7}{|l|}{ Postoperative complication } \\
\hline yes & 159 & 17.4 & $68(42.8)$ & 310.17 & 0.0001 & $93.03(39.27-220.42)$ \\
\hline No & 753 & 82.6 & $6(0.8)$ & 310.17 & 0.0001 & 1 \\
\hline \multicolumn{7}{|l|}{ Type of complications } \\
\hline None & 753 & 82.6 & $6(0.8)$ & 697.64 & & 1 \\
\hline Hyperthermia & 49 & 5.4 & $7(14.3)$ & 17 & 0.0001 & $20.75(6.67-64.48)$ \\
\hline Coma & 36 & 3.9 & $36(100)$ & 670.89 & 0.0001 & $125.5(59.56-278.46)^{a}$ \\
\hline Nausea and vomiting & 34 & 3.7 & $4(11.8)$ & 31.19 & 0.0001 & 16.6(4.44-61.93) \\
\hline Sepsis & 14 & 1.5 & 14(100) & 532.62 & 0.0001 & $125.5(59.56-278.46)^{a}$ \\
\hline Cardiorespiratory arrest & 3 & 0.3 & $3(100)$ & 249.99 & 0.0001 & $125.5(59.56-278.46)$ \\
\hline Anaemia & 2 & 0.2 & $1(50)$ & 52.57 & 0.0001 & 24.50(6.95-2231.07) \\
\hline Aspiration pneumonia & 2 & 0.2 & $2(100)$ & 187.24 & 0.0001 & $125.5(59.56-278.46)^{a}$ \\
\hline Respiratory arrest & 1 & 0.1 & $1(100)$ & 125.50 & 0.0001 & $125.5(59.56-278.46)^{a}$ \\
\hline Others $^{b}$ & 18 & 1.3 & $0(0)$ & & & \\
\hline
\end{tabular}




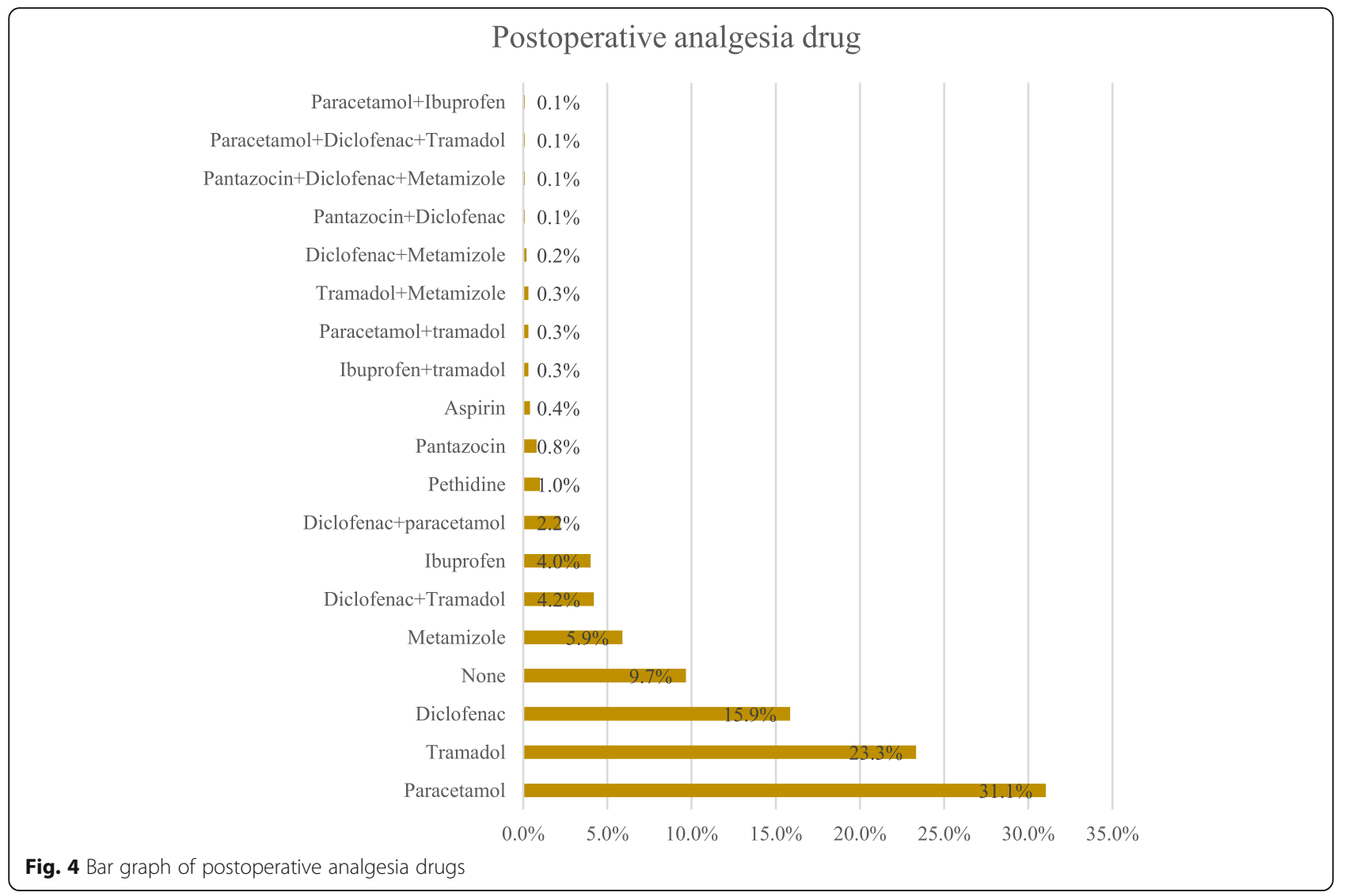

under GA. Importantly, the study reveals insufficient areas of provided anaesthesia services, key elements that need to be addressed when planning for an improved future anaesthesia practice in the region.

From this study, 83 patients (9.0\%) died after an operation under GA, which represented an overall perioperative mortality rate after GA of 90 per 1000 . According to the definition in this study, GA was implicated directly or indirectly in 38 of the 83 deaths (45.8\%) who died within $24 \mathrm{~h}$, representing a GA related mortality rate of $4.1 \%$ or 41 per 1000 procedures. Both the overall perioperative and the GA related mortality rates were very high. However, there was an overall decrease mortality over time reflecting an improvement that may be related to gained experience overtime by providers and employment of qualified anaesthetic nurses since the infrastructure was almost the same. Other reasons may additionally explain this improvement, but would require different and more data and is either not the scope of this study. The findings of this study are consistent with trends in decreased mortality observed in Africa and worldwide [2, 32-35]. However, efforts should be made to further lowering the mortality.

Few studies have reported specific mortality after a GA in developing countries but a lot of studies exist on perioperative mortality. Similar to the results in this study, Rickard et al. in Rwanda reported an overall perioperative mortality of $6.5 \%$ and the $24 \mathrm{~h}$ mortality of $35 \%$ [22]. Ariyamata et al., in their study in high, middle and low income countries, reported a perioperative mortality within $24 \mathrm{~h}$ between 8 and $20 \%$ higher than in Togo, Kenya, Zambia and in the African Surgical Outcomes study (ASOS) but lower than observed in our study $[24,26,27,33,34,36]$. In the European Surgical Outcomes Study (EuSOS), Pearse et al. noted a 7 days' mortality of $4 \%$ with wide variability between countries $(1.2 \%$ in Ireland and $21.5 \%$ in Latvia) [35]. The high rate observed in this study might be due the fact that the hospitals in this study are poorly equipped and lack human resources. Non-trained providers were administrating GA. Drugs supply is also questionable. None of the hospitals had a fully working anaesthesia machine during the period of study. A recent study done by Blaise Pascal et al. on practice of standard monitoring in the same region support these hypotheses [37]. Lack of proper infrastructure, drugs, equipment and trained providers are facts limiting safe anaesthesia [38, 39]. Efforts should then be made by these hospitals to procure all the necessary drugs and equipment, to improve the infrastructure and to employ trained providers or participate in their training for safe GA. 
Almost $10.6 \%$ of deaths (9 patients) occurred intraoperatively. The high intraoperative rate in this study corroborates the results observed by Prin et al. in Malawi [25]. This raised a question on the level of knowledge and skills of anaesthesia providers on management of intraoperative emergencies such as cardiac arrest which was fatal in this study and obviously a need to empower them with adequate knowledge and skills in cardiorespiratory resuscitation and intraoperative emergencies management.

This study also found that a big number of patients died in the ICU postoperatively. In the ASOS, Biccard et al. observed a high mortality rate in patients admitted in ICU postoperatively compared to those who were not admitted [34]. High mortality in ICU can be explained by the fact that both hospitals didn't have proper ICU facilities. In the settings of this study, all so-called ICUs were under equipped. They didn't have ventilators, monitoring, 100\% oxygen, syringe-pumps as well as other important devices for ICU. Strictly speaking they were more like high dependency units. Patients who require ICU admission are usually very sick, implying that a low setting ICU represents an additional risk which may impact their outcome negatively $[6,7,40]$.

This study demonstrated that age, especially extreme ages like neonates and senior adults, were significantly associated with increased death. This coincides with several reports recognizing extreme age as a factor of perioperative mortality $[2,4,6,22,28,34,35,41,42]$. The high number of deaths in the neonatal group, with extension to the paediatric, expresses the poor quality of paediatric anaesthesia in the region and a need to implement changes to reduce mortality in this group. This can be achieved by strengthening the available workforce in paediatric anaesthesia by refresher courses and seminars in paediatric anaesthesia, training of more anaesthesia providers and improvement of the infrastructure.

Emergency procedures increased the risk of death and corroborates the results from Europe, Australia and lowincome and middle-income countries [32, 35, 43]. Emergency patients are most of the time very sick or with a life-threatening condition that increased their mortality risk $[2,12,34,44]$. Furthermore, emergency patients are often not well optimized before surgery especially in low-income countries where drugs are not available all the time. Poor preoperative optimization has been found associated with high mortality $[35,45,46]$. In this study, the poor preoperative optimization state correlated to the presence of one single deranged vital sign preoperatively and was highly associated with increased mortality risk. Similarly, Hollis et al. identified deranged vital signs as a factor of Critical Postoperative Complications [47]. Deranged vital signs at admission, used in systematic scores like in the Early Warning Score (EWS), have been associated with increased death in the ICU, the emergency departments as well as in surgery [48-52]. In lowincome countries, access to sophisticated preoperative laboratory tests and imaging is challenging, thus underscoring the vital importance of using the EWS systematically. This is a simple approach, easy and cheap and may help the clinician to detect patient deterioration and guide the anaesthesia plan. However, since this study didn't evaluate the EWS specifically, further prospective studies are needed to confirm EWS would be an important of EWS preoperative assessment tool in anaesthesia.

Increased ASA PS correlates with high mortality risk $[2,22,24,25,34,35]$. The present study corroborates this, showing that ASA PS 3 and 4 patients were at higher risk of death. Special attention and optimization of these patients should be taken before any surgery to improve their outcome.

Neither the qualification nor the experience of the anaesthesia providers was associated with death. In comparison to this study, the Cochrane review done by Lewis et al. concluded that it was not possible to draw a clear decision whether a physician versus non -physician anaesthesia providers, had any impact on safe anaesthesia and outcome [53].

This study revealed that gas induction and intubation multiplied the risk of dying by a factor of 2 and 1.9 respectively. This is consistent with a report documenting from 21 countries with resource-limited settings, that GA without intubation was associated with lower mortality compared to GA with intubation [54]. The anaesthesia settings of the hospitals in this study were lower. All hospitals didn't have proper anaesthesia machines with mechanical ventilation, proper system of oxygen procurement, drugs and good monitoring. In such situations, intubating a patient represents a high risk of hypoxia, hypoventilation, hypercapnia and all other cascades which ineluctably may lead to death $[6-8,12]$. Furthermore, in this study, gas maintenance of anaesthesia carried higher risk of death compared to iv maintenance. This situation illustrates once more a problem with management of intubated patients. In general, Ketamine was the most used drug for iv induction and maintenance. This might have explained the large use of atropine as a premedication drug. In Africa, Ketamine is the most available drugs, and because of its properties it is easy to use even by non-trained providers. Ketamine anaesthesia allows maintenance of spontaneous respiration, and BP with slight increase in BP and provides analgesia [27, 33, 54-56]. Thus, in limited setting conditions, for procedures where the risk of aspiration is not very high, it could be much better to keep the patient spontaneously breathing without intubation. This is often successfully achieved with ketamine. Contrary, intubation of 
a patient requires in general more resources, equipment, monitoring and good skills for a safe technique. Intubation may become hazardous and increase the risk of unwanted events and death if these prerequires are not met. Further studies are needed to confirm the safety of Ketamine use in lower setting conditions. Additionally, in order to better take care of intubated patient, which is the gold standard for GA, and reduce the risk under GA with intubation, hospitals and all stakeholders should include training of anaesthesia providers in their plan as well as procurement of equipment, drugs and oxygen for safe anaesthesia and surgery. Employing regional anaesthesia could also help to avoid unsafe general anaesthesia $[9,15,16,18]$.

Occurrence of any complication at induction or during maintenance of anaesthesia was significantly associated with increased risk of death. These results corroborate the findings of the International Surgical Outcomes Study [57].

Patients who had a laparotomy/visceral surgery and patients with anal malformations presented high risk of death compared to orthopaedics patients. Laparotomy/ visceral surgery has been identified as a factor of death in several studies [4, 27, 32, 33, 57, 58]. Laparotomy/visceral surgery patients are often very sick patients. The patients in the present study were operated under nonoptimal GA, primary due to lack of resources. They were often not intubated implying increased risk of aspiration and aspiration pneumonia. Whenever they were intubated proper mechanical ventilation and proper monitoring were not used. All those conditions are well known associated with high mortality [12, 25, 34, 59].

Long duration of procedure (procedure more than $2 \mathrm{~h}$ ) was associated with high mortality. Our results are similar to those obtained by Phan et al. who found significantly higher rates of any complication with prolonged anaesthesia [60]. As observed in this study, Cheng et al. in a systematic review and meta-analysis observed that the likelihood of complications increased significantly with prolonged operative duration, approximately doubling with operative time thresholds exceeding 2 or more hours [61].

A large number of patients (64.5\%) were admitted directly in their wards from the operating room. Only $2.3 \%$ of patients were admitted in a PACU. This practice is unsafe since postoperative period is crucial for the safety of the patient and life-threatening complications happen during this period. Patients should be admitted in specific postoperative recovery given that PACU has help to improve outcome after surgery [38, 62]. Furthermore, patients left postoperatively in the operating room presented high risk of death. In the context of this study, staying in the operating room meant that patient couldn't wake up early from GA and needed proper intensive care which couldn't be acceded for due to lack of ICU infrastructure. Lack of admission or a late admission to ICU have been found as factors of high mortality postoperatively [38, 40,63, 64]. Proper PACUs and ICUs should be implanted in theses hospital in order to decrease mortality.

Postoperative pain management was not implemented systematically and featured by the use of drugs with poor analgesia effect. This demonstrates a poor pain postoperative management and a need for improvement in this area of anaesthesia. Pain control is a core element of GA [3].

\section{Limitations}

This study has provided data for the practice of GA in Butembo. As a baseline study, it will help further research in the field as a comparison where no previous data was available. The study covered most of the aspect of GA from preoperative period to postoperative period.

This study revealed that iv anaesthesia maintenance especially with Ketamine anaesthesia was safe in such low settings. The study has also revealed areas of improvement for safe practice of GA in the region. These are paediatric anaesthesia with emphasis on neonatal anaesthesia, postoperative anaesthesia care, intensive care management, enhance recovery after surgery, cardiopulmonary resuscitation and perioperative pain management. It has elicited a need for trained anaesthesia providers, appropriate drugs, equipment and infrastructure.

However, this study has some limitations. As a retrospective study some data were missing. This study used a simple logistic regression and no confounding factors were searched. As a baseline study in a low setting area, the objective was limited to determine all possible causes of death. Nevertheless, there is a need of further prospective research to elucidate and discriminate the factors. The definition of anaesthesia relation to death was only time linked and this study couldn't state the cause of death. Although, it has been confirmed that anaesthesia complications occur early, there is a room to clarify this association to death by further research which will consider a peer review of each case of death to set the association to death.

\section{Conclusion}

GA related mortality rate is high in Butembo but the trend is decreasing over time. Although the morbidity rate is high, it is comparable with other countries worldwide. Preoperative factors increasing mortality risk are the neonatal age and age equal or more than 50 years, emergency procedures, ASA PS (ASA equal or more than 2), single deranged vital signs at admission. Presenting a complication at any time intraoperatively was a factor increased risk of death. Intubation compared to non-intubation carried more risk of death. Cardiac arrest 
was a fatal complication. Postoperative deranged vital signs increased mortality. Presenting a complication postoperatively was a factor of death as well as being left in operating room as recovery place. Pain management was not adequate. There is a huge need to improve the practice of GA in the region by training more anaesthesia providers, proper patients monitoring, enhancing the infrastructure, equipment and drugs procurement and considering regional anaesthesia whenever possible.

\section{Abbreviations \\ AMR: Avoidable mortality rate; ASA PS: American Association of Anesthesiologists Physical Status; COM: College of Medicine; COMREC: College of Medicine Research and Ethics Committee; CUG: Cliniques Universitaires du Graben; DRC: Democratic Republic of the Congo; EWS: Early warning score; GA: General Anaesthesia; ICU: Intensive Care Unit; PACU: Postoperative anaesthetic care unit; UCG: Université Catholique du Graben}

\section{Acknowledgements}

The authors would like to thank the Matanda Hospital and the CUG administrations. The authors would also like to thank the "Bourse d'Excellence Bringmann aux Universités Congolaise" (BEBUC, www. foerderverein-unikinshasa.de), the Elser - Kroener - Fresenius Stiftung and Holger- Poehlmann-Stiftung foundations, and the Safe Anaesthesia Worldwide for the support of the master's training in Anesthesia and Intensive Care of Dr. Furaha Nzanzu Blaise Pascal at the College of Medicine of the University of Malawi.

\section{Authors' contributions}

FNBP: Helped in designing the study, data collection, data analysis and wrote the manuscript. AM: Helped in collecting data. FN: Helped in designing the study and reviewed the manuscript. ABD: Helped in data interpretation and reviewed the manuscript. GP: Helped in supervising the work, data interpretation and reviewed the manuscript. All authors have read and approved the manuscript.

\section{Authors' information}

FNBP, MD, Mmed: Department of Anaesthesia and Intensive care, College of Medicine, University of Malawi. Assistant Lecturer at Faculty of Medicine, Université Catholique du Graben,Democratic Republic of the Congo (DRC) Tel +265880993663 Email blaisepascal.furaha@gmail.com Corresponding Author. AM: Nurse Anaesthetist, Matanda Hospital of Butembo, DRC.FN, MBBS, MMED: Head of Department of Anaesthesia and Intensive care, College of Medicine, University of Malawi. ABD, MD, PhD: Division of Emergencies and Critical Care,Rikshospitalet, Oslo University Hospital, Oslo, Norway. GP, Dr. med., M.A. (pol.sc), M.A. (phil), FCAl (hon.): Professor of Anaesthesiology and Intensive Care at College of Medicine,University of Malawi.

\section{Funding}

Not applicable.

\section{Availability of data and materials}

All data and material used in this article are available at any request from the corresponding author.

\section{Ethics approval and consent to participate}

This study was a low-risk research. The protocol was submitted and obtained approval from the "the Comité Ethique du Nord Kivu" (CENK) in Butembo in the DRC under number CENK N $007 / 2018$ and from the College of Medicine Research Ethics Committee (COMREC) in Malawi under number P.07/18/ 2431. Participants' consent was waived by both Ethics committees. The data were anonymous on the data collecting form and in the electronic Data Base. All research was performed in accordance with relevant guidelines/ regulations in these hospitals.

\section{Consent for publication}

Not Applicable.

\section{Competing interests}

All the authors declare that they have no competing interests.

\section{Author details}

'Department of Anaesthesia and Intensive Care, College of Medicine, University of Malawi, Blantyre, Malawi. ${ }^{2}$ Faculty of Medicine, Université Catholique du Graben, Butembo, Democratic Republic of the Congo. ${ }^{3}$ Matanda Hospital of Butembo, Butembo, Democratic Republic of the Congo. ${ }^{4}$ Division of Emergencies and Critical Care, Rikshospitalet, Oslo University Hospital, Oslo, Norway.

Received: 21 December 2020 Accepted: 15 February 2021 Published online: 23 February 2021

\section{References}

1. Schiff JH, Wagner S. Trends in Anaesthesia and critical care anesthesia related mortality? A national and international overview. Trends Anaesth Crit Care. 2016;9:43-8.

2. Bainbridge D, Martin J, Arango M, Cheng D. Perioperative and anaestheticrelated mortality in developed and developing countries : a systematic review and meta-analysis. Lancet. 2012;380:1075-81.

3. McQueen K, Coonan T, Ottaway A, Dutton RP, Nuevo FR, Gathuya Z, et al. Anesthesia and Perioperative care. In: Debas HT, Donkor P, Gawande A, Jamison DT, Kruk ME, Mock CN, editors. Essentiel Surgery. 3rd ed. Washington: World Bank Group; 2015. p. 263-77.

4. Braz LG, Braz DG, da Cruz DS, Fernandes LA, Modolo NSP, Braz JRC Mortality in anaesthesia:a systematic review. Clinics. 2009;64(10):999-1006.

5. Ozgediz D, Jamison D, Cherian M, Mcqueen K. The burden of surgical conditions and access to surgical care in low- and middle-income countries. Bull World Health Organ. 2008;86(8):646-7.

6. Khan M, Khan FA. Anesthetic deaths in a developing country. M E J Anesth. 2007;19(1):159-72.

7. Khan FA, Merry AF. Improving anesthesia safety in low-resource settings. Anesth Analg. 2018;126(4):1312-20.

8. Houwe P v. Anesthesia in Africa : quo vadis? Acta Anaesthesiol Belg. 2007: 58(3):161-2.

9. Abeysekera A, Bergman IJ, Kluger MT, Short TG. Drug error in anaesthetic practice : a review of 896 reports from the Australian incident monitoring study database. Anaesthesia. 2005;60:220-7.

10. Hove LD, Steinmetz J, Christoffersen JK, Møller A, Nielsen J, Schmidt H. Analysis of deaths related to anesthesia in the period 1996-2004 from closed claims registered by the Danish patient insurance association. Anesthesiology. 2007;106(4):675-80.

11. Hendel S, Coonan T, Thomas S, Mcqueen K. The rate-limiting step : the provision of safe anesthesia in low-income countries. World J Surg. 2015; 39(4):833-41.

12. Steadman J, Catalani B, Sharp C, Cooper L. Life-threatening perioperative anesthetic complications : major issues surrounding perioperative morbidity and mortality. Trauma Surg Acute Care Open. 2017;2:1-7.

13. Haynes AB, Weiser TG, Berry WR, Lipsitz SR, Breizat A-HS, Dellinger EP, et al. A surgical safety checklist to reduce morbidity and mortality in a global population. N Engl Med. 2009;360(5):491-9.

14. Beecher HK, Todd DP. A study of the deaths associated with anesthesia and surgery: based on a study of 599, 548 anesthesias in ten institutions 19481952, inclusive. Ann Surg. 1954;140(1):2-35.

15. Tiret L, Desmonts JM, Hatton F, Vourc'h G. Complications associated with anaesthesiaa - prospective survey in France. Can Anaesth Soc J. 1986;33(3): 336-44.

16. Lienhart A, Auroy Y, Péquignot F, Benhamou D, Warszawski J, Bovet M, et al. Survey of anesthesia-related mortality in France. Anesthesiology. 2006; 105(6):1087-97.

17. Fowler AJ, Review A. Review of recent advances in perioperative patient safety. Ann Med Surg. 2013;2(1):10-4

18. Kawashima Y, Takahashi S, Suzuki M, Morita K, Irita K, Iwao Y, et al. Anesthesia-related mortality and morbidity over a 5-year period in 2,363,038 patients in Japan. Acta Anaesthesiol Scand. 2003;47:809-17.

19. Löfgren J, Kadobera D, Forsberg BC, Mulowooza J, Wladis A, Nordin P. Surgical services : access and coverage surgery in district hospitals in rural Uganda-indications, interventions, and outcomes. Lancet. 2015;385:S18.

20. Hansen D, Gausi SC, Merikebu M. Anaesthesia in Malawi: complications and deaths. Trop Dr. 2000;30(3):146-9. 
21. Brouh Y, Tétchi DY, Yaïch P, Ouattara A, Koffi N. Bredou, et al. La pratique de I ' anesthésie en Côte d' Ivoire. RAMUR. 2011;16(1):48-53.

22. Rickard JL, Ntakiyiruta G, Chu KM. Associations with perioperative mortality rate at a major referral Hospital in Rwanda. World J Surg. 2016;40(4):784-90.

23. Heywood AJ, Wilson IH, Sinclair JR. Perioperative mortality in Zambia. Ann R Coll Surg Engl. 1989;71:354-8.

24. Lillie EMMA, Holmes CJ, O'Donohoe EA, Bowen L, Chadwick LT, Ngwisha, Ahmed $Y$, et al. Avoidable perioperative mortality at the University Teaching Hospital , Lusaka, Zambia : a retrospective cohort study. Can J Anesth. 2015:62:1259-67.

25. Prin M, Pan S, Phelps J, Phiri G, Li G, Charles A. Intraoperative mortality in Malawi. Anesth Analg. 2019;128(6):1286-91.

26. Maman AFO-B, Tomta K, Ahouangbevi S, Chobli M. Deaths associated with anaesthesia inTogo. West Africa Trop Doct. 2005;35:220-2.

27. Maman AFO-B, Agbétra N, Egbohou P, Sama H, Chobli M. Morbiditémortalité périopératoire dans un pays en développement : expérience du CHU de Lomé (Togo). Ann Fr Anesth Reanim. 2008:27:1030-3.

28. Davies JF, Lenglet A, van Wijhe M, Ariti C. Global surgery perioperative mortality : analysis of 3 years of operative data across 7 general surgical projects of M edecins sans Fronti eres in Democratic Republic of Congo Central African Surgery. 2016;159(5):1269-78.

29. Cikwanine B, Nyakio O, Birindwa A, Chasinga B, Mukwege MD, DIOUF E. Anesthésie pour Césarienne en Urgence Absolue à l'hôpital de Panzi. RAMUR. 2013;18(4):15,

30. Furaha Nzanzu BP, Kyalwahi R, Malisawa A. Issue des complications anesthésiques au cours de la césarienne dans les hôpitaux du Diocèse de Butembo-Beni. Méd Afr Noire. 2017:64(7):385-92.

31. Ahuka OL. Les priorités chirurgicales en milieu rural tropical. Kisangani: Presses universitaires de l'Université de Kisangani; 2002. p. 32-42.

32. Ng-kamstra JS, Arya S, Greenberg SLM, Kotagal M, Arsenault C, Ljungman D, et al. Perioperative mortality rates in low-income and middle-income countries : a systematic review and meta-analysis. BMJ Glob Health. 2018; 3(3):e00810.

33. Sileshi B, Newton MW, Kiptanui J, Shotwell MS, Wanderer JP, Mungai M, et al. Monitoring anesthesia care delivery and perioperative mortality in Kenya utilizing a provider-driven novel data collection tool. Anesthesiology. 2017;127(2):250-71.

34. Biccard BM, Madiba TE, Kluyts H, Munlemvo DM, Madzimbamuto FD, Basenero A, et al. Perioperative patient outcomes in the African surgical outcomes study : a 7-day prospective observational cohort study. Lancet. 2018;391(110130):1589-98

35. Pearse RM, Moreno RP, Bauer P, Pelosi P, Metnitz P, Spies C, et al. Mortality after surgery in Europe : a 7 day cohort study. Lancet. 2011;380(9847):1059-65.

36. Ariyaratnam R, Palmqvist CL, Hider P, Laing GL, Stupart D, Wilson L, et al. Toward a standard approach to measurement and reporting of perioperative mortality rate as a global indicator for surgery. Surgery. 2015; 158:17-26.

37. Blaise Pascal FN, Musavuli PK, Ketha JK, Sikakulya FK, Barratt-due A, Castner T, et al. Practice of standard monitoring during anaesthesia in hospitals of north Kivu : a survey of health facilities of the health antenna of Butembo. BMC Health Serv Res. 2020;20:e262.

38. Walker IA, Bashford T, Fitzgerald JE, Wilson IH. Improving anesthesia safety in low-income regions of the world. Curr Anesth Rep. 2014;4:90-9.

39. Botney R. Improving patient safety in anesthesia:a success story? Int J Radiat Oncol Biol Phys. 2008;71(1, Supplement):S182-6.

40. Gillies MA, Harrison EM, Pearse RM, Garrioch S, Haddow C, Smyth L, et al. Intensive care utilization and outcomes after high-risk surgery in Scotland: a population-based cohort study. Br J Anaesth. 2017;118(1):123-31.

41. Pignaton W, Braz JRC, Kusano PS, Modolo MP, de Carvalho LR, Braz MG, et al. Perioperative and Anaesthesia-related mortality an 8-year observational survey from a tertiary teaching hospital. Medicine (Baltimore). 2016;95(2):e2208.

42. Cronjé L. A review of paediatric anaesthetic-related mortality, serious adverse events and critical incidents A review of paediatric anaestheticrelated mortality, serious adverse events and critical incidents. South African J Anaesth Analg. 2015;21(6):147-53.

43. ANZCA. Safety of Anaesthesia. A review of anaesthesia-related mortality reporting in Australia and New Zealand 2012-2014; 2017. p. 38.

44. Story DA. Best Practice \& Research Clinical Anaesthesiology Postoperative mortality and complications. Best Pract Res Clin Anaesthesiol. 2011;25:31927.
45. Sethi A, Debbarma M, Narang N, Saxena A, Mahobia M. Impact of targeted preoperative optimization on clinical outcome in emergency abdominal surgeries : a prospective randomized trial. Anesth Essays Res. 2019;12(1): $149-54$.

46. Landoni G, Pisano A, Lomivorotov V, Alvaro G, Hajjar L, Paternoster G, et al. Randomized evidence for reduction of perioperative mortality: an updated consensus process. J Cardiothorac Vasc Anesth. 2017;31(2):719-30.

47. Hollis RH, Graham LA, Lazenby JP, Brown DM, Taylor BB, Heslin MJ, et al. A role for the early warning score in early identification of critical postoperative complications. Ann Surg. 2016;263(5):918-23.

48. Albur M, Hamilton F, Macgowan AP. Early warning score : a dynamic marker of severity and prognosis in patients with gram - negative bacteraemia and sepsis. Ann Clin Microbiol Antimicrob. 2016;15:23.

49. Baker T, Blixt J, Lugazia E, Schell CO, Mulungu M, Milton A, et al. Single deranged physiologic parameters are associated with mortality in a lowincome country. Crit Care Med. 2015;43:2171-9.

50. Garcea G, Ganga R, Neal CP, Ong SL, Dennison AR, Berry DP. Preoperative early warning scores can predict in-hospital mortality and critical care admission following emergency surgery. J Surg Res. 2010;159(2):729-34.

51. Somasundaram UR, Santhiyagappan E. A tertiary care Centre experience of modified early warning score (MEWS) in post-operative patients. Int Surg J. 2018;5(11):3536.

52. Brekke IJ, Puntervoll LH, Pedersen PB, Kellett J, Brabrand M. The value of vital sign trends in predicting and monitoring clinical deterioration : a systematic review. PLoS One. 2019;14(1):e0210875.

53. Sr L, Nicholson A, Af S, Alderson P. Physician anaesthetists versus nonphysician providers of anaesthesia for surgical patients ( Review ). Cochrane Database Syst Rev. 2014;7.

54. Ariyo P, Trelles M, Helmand R, Amir Y, Hassani GH, Mfatavyanka J, et al. Providing anesthesia Care in Resource-limited Settings a 6-year analysis of anesthesia services provided at Médecins Sans Frontières facilities. Anesthesiology. 2016;124(3):561-9.

55. Anderson GA, Ilcisin L, Abesiga L, Mayanja R, Benetiz NP, Ngoai J, et al. Surgical volume and postoperative mortality rate at a referral hospital in Western Uganda : measuring the lancet commission on global surgery indicators in low-resource settings. Surg Glob Med. 2017;161(6):1710-9.

56. Koka R, Chima AM, Sampson JB, Jackson EV, Ogbuagu OO, Rosen MA, et al. Anesthesia practice and perioperative outcomes at two tertiary care hospitals in Freetown, Sierra Leone. Anesth Analg. 2016;123(1):213-27.

57. The International Surgical Outcomes Study group. Global patient outcomes after elective surgery: prospective cohort study in 27 low-, middle- and high-income countries. Br J Anaesth. 2016 Nov;117(5):601-9.

58. Spence RT, Hampton M, Pluke K, Kahn M, Chinyepi N, Elmusbahi M, et al. Factors associated with adverse events after emergency laparotomy in Cape Town, South Africa : identifying opportunities for quality improvement. J Surg Res. 2016;206(2):363-70.

59. Prin M, Eaton J, Mtalimanja O, Charles A. High elective surgery cancellation rate in Malawi primarily due to infrastructural limitations. World J Surg. 2018, 42(6):1597-602.

60. Phan K, Kim JS, Kim JH, Somani S, Di Capua J, Dowdell JE, et al. Anesthesia duration as an independent risk factor for early postoperative complications in adults undergoing elective ACDF. Glob Spine J. 2017;7(8):727-34.

61. Cheng H, Clymer JW, Chen BP, Sadeghirad B, Ferko NC, Cameron CG, et al. Prolonged operative duration is associated with complications : a systematic review and. J Surg Res. 2018;229:134-44.

62. Davidson M, Litchfield K. Patient recovery and the post-anaesthesia care unit (PACU). Anaesth Intensive Care Med. 2018;19(9):457-60.

63. Goldhill DR. Preventing surgical deaths: critical care and intensive care outreach services in the postoperative period. Br J Anaesth. 2005;95(1):8894.

64. Stefani LC, Gutierrez CDS, de Castro SMJ, Zimmer RL, Diehl FP, Meyer LE, et al. Derivation and validation of a preoperative risk model for postoperative mortality ( SAMPE model ): an approach to care stratification. PLoS One. 2017;12(10):1-14.

\section{Publisher's Note}

Springer Nature remains neutral with regard to jurisdictional claims in published maps and institutional affiliations. 